\title{
A Research on American Young Adults' Ego-Identity/Perceived Organizational Support and Job Involvement
}

\author{
Jing $\mathrm{Wu}$ \\ Business School of Jianghan University, Wuhan, China \\ E-mail: jeannewu@163.com
}

\begin{abstract}
This paper evaluated the relationship between American Young Adults' Ego-Identity (EI) and their Job Involvement (JI). The paper also studied the moderating effect of the Perceived Organizational Support (POS). The study was conducted using an online survey; 109 of the 111 collected survey responses were valid. Correlation and regression analyses showed that JI was negatively related to EI Achieved status. With improvement in POS, individual's JI increased significantly under the identity status of Foreclosed. Individual's gender has significant effect on their EI. Individual's race has significant effect on their JI.
\end{abstract}

Keywords-Ego-identity Status; Perceived Organizational Support; Job Involvement

\section{INTRODUCTION}

Mckelvey and Sekaran (1977) defined job involvement as " the merging of a person's ego identity with his or her job " , therefore, an employee's job involvement is related to the degree of the unity of his/her personal identity and work. This definition can be traced back to the statement of Gurin, Veroff, and Feld (1960), which was the extent to which individuals seek some expression and actualization of the self in their work, and Lodahl and Kejner (1965) defined JI as the extent that people psychologically identify with their work and the importance of self-image for them .Mckelvey and Sekaran (1977) also mentioned that an individual is concerned about the degree of their identity that is shaped by their job. The authors elaborated further by stating that an individual often has a strong desire to satisfy the need for ego identity and development in their job.

This clearly indicates that in the early 1970's, some scholars believed that there is a strong correlation between individuals' work inputs and their ego-identity. However, there is no empirical support for such believes. Rabinowitz and Hall (1977) argued that job involvement is a personal trait. Therefore, it is less likely to be influenced by organizational factors but rather it is more likely to be influenced by personal characteristics. For example, an individuals' age is positively correlated with the degree of job involvement and men's job commitment is higher than women's; Brown (1996) noted that the degree of individuals' job involvement was affected by their personality and environmental variables; Riketta (2005)'s meta-analysis on organizational identification indicates that the organizational identification has a higher impact on employees' job involvement than job satisfaction; Gorji (2014) found that the nurses' job involvement and perceived organizational support were significantly correlated in Iranian General Hospital emergency rooms.

This paper attempts to determine the relationship between American young adults' Ego-identity and their job involvement and to clarify the moderating influence of perceived organizational support.

\section{DEFINITION OF THREE MAIN CONCEPTS AND HYPOTHESIS DEVELOPMENT}

Kanungo (1979) defined Job Involvement (JI) as "a general cognitive status, as long as the work is perceived to be prominent to help meet the needs and expectations of the individual, the individual will have a psychological work identity."

Rhoades and Eisenberger (2002) defined Perceived Organizational Support (POS), as employees having a "general belief that their work organization values their contributions and cares about their well-being."

Erikson (1968) stated that Ego-Identity "is the awareness of the fact that there is a self-sameness and continuity to the ego's synthesizing methods, the style of one's individuality, and that this style coincides with the sameness and continuity of one's meaning for significant others in the immediate community." Some individuals are not fully explored and, they are premature to accept the values, beliefs, lifestyles of the significant others (parents, teachers, friends etc.). Ego-identity is reached in early admission status (foreclosed). Some individuals are neither exploration nor pondering, and there are no significant others give them any kind of help or guidance, that is called identity confusion (diffused). Some individuals are under ongoing exploration enter a crucial period of individual life and suffer a crisis of identity. They must go through a time of crisis to move on. This state is identity moratorium (moratorium). Only individuals who have fully explored ego identity, tried a variety of life possibilities (including two aspects: ideology, such as political opinions, religious choices, and values and; interpersonal skills, such as friendship, dating, family, gender roles, etc.), experienced a critical turning point named identity crisis and finally show commitment to both self-ideology and the way to get along well with others, and have a clear understanding of both future career and life goals, will achieve ego-identity achieved status (achieved).

Based on the literature, this paper hypothesizes: 
H1 -Individual's EI (Ego Identity)Achieved status will be significantly related with JI(Job Involvement);

H2 - Individual' POS(Perceived Organizational Support) will be positively related with JI;

H3 -For different EI status, POS shows different impacts on individual's JI as a moderator.POS shows positive impacts for EI achieved to their JI.

H4 - Individual's BC (Biographical Characteristics such as gender,age,education and reace)will be related to EI Status.

H5-Individual's BC will be related to JI .

\section{A. Research Design}

Items for Ego-Identity (EI) Process Questionnaire /Survey of Perceived Organizational Support (POS)/Job Involvement (JI) Factorial Structure of 6-item short measure version scale completed a questionnaire to determine the relationship between young adults' EI and their JI. The moderating effect of POS on the relationship was also studied.

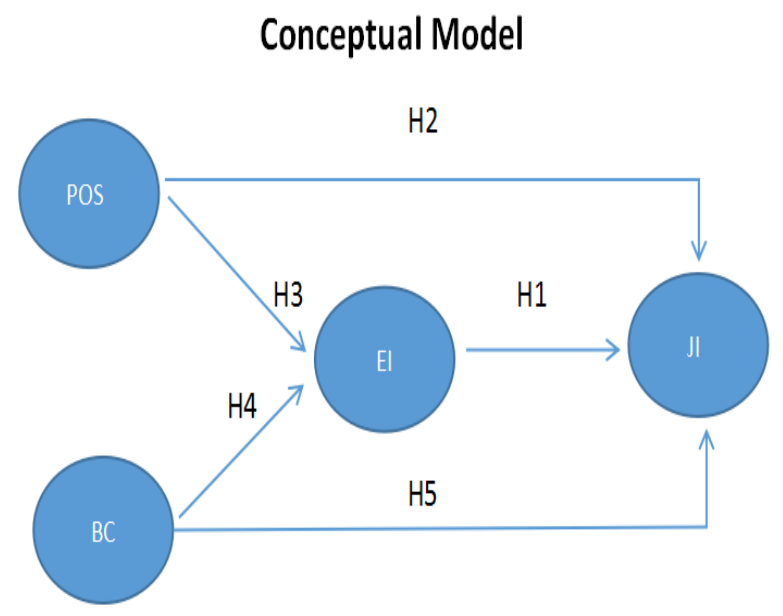

Figure.1. The moderating effect of POS on the relationship

\section{B. Sample and Procedure}

Items for Ego Identity Process Questionnaire were obtained from (Balistreri et al., 1995). There were 32 item questions in the survey which represent a reduction of $50 \%$ when compared to Bennion \& Adams (1986) 64 items questionnaire. The reduction, however, did not materially change the questionnaire but made it easier to complete. This questionnaire measures eight dimension problems including values, career goal, political view, and religious belief, friendship view, dating view, family view and gender roles. In order to test respondents' Ego-Identity Exploration (EIE) and Ego-Identity Commitment (EIC) status, a 1 - 6 Likert scale was used in the questionnaire. Each of EIE and EIC had a total 16 items, of which 10 positive scoring items and 6 negative scoring items. The 1 - 6 Likert scale represented strongly-disagree, disagree, compare-disagree, compare-agree, agree, strongly-agree. After summing the final score separately, a higher EIE score represents higher degree of EI Exploration; and a higher EIC score, represents a higher degree of EI Commitment. The classifications of the four types of status of EI are presented in Table I.

TABLE I. CLASSIFICATION AND STANDARD OF EGO-IDENTITY

\begin{tabular}{c|c}
\hline EI Classification & Standard of Classification \\
\hline EI Achieved & EIE $\geq$ median \& EIC $\geq$ median \\
EI Moratorium & EIE $\geq$ median \& EIC $<$ median \\
EI Foreclosed & EIE $<$ median \& EIC $\geq$ median \\
EI Diffused & EIE $<$ median \& EIC $<$ median \\
\hline
\end{tabular}

C. Survey of Perceived Organizational Support

The scale has 16 questions, of which 9 are positive scoring items and 7 are negative scoring items, used a Likert scale of 1-7 that represented strongly disagree, disagree, compare disagree, neither agree nor disagree, compare agree, agree and strongly agree. After summing the negative scoring items, and finally calculating the score of the total 16 POS questions, a higher score represents a higher POS level.

D. Job Involvement Factorial Structure of 6-item Short Measure Version

Lodahl and Kejner emphasized that 6 of the 20 items had highest loadings on the first principal axis in both samples, and formed into a short version of the scale, which included 5 positive scoring items and 1 negative scoring item, four levels Likert scale was used. 1-4 points, represent strongly disagree, disagree, agree and strongly agree respectively. After summing the total 6 items, the higher score represents a higher individual's JI. Mckelvey and Sekaran (1977) used this simple version in their research.

\section{E. The Investigation Process}

111 young American adults were invited to fill out the online questionnaire, 109 of the 111 collected responses were valid. The recovery rate is $98 \%$.

The Ego Identity Scale was split into two scales, EIE and EIC, according to previous definition. The Cronbach coefficients of EIE, EIC, JI, and POS were 0.736, 0.737, 0.695 , and 0.934 respectively. All had good reliability.As Table II shows, the sample was a good representative of the American work force. 
TABLE II.GENERAL INFORMATION ABOUT THE STATISTICS

\begin{tabular}{|c|c|c|c|}
\hline $\begin{array}{c}\text { Biographical } \\
\text { Characteristics }\end{array}$ & Category & $\begin{array}{l}\text { Number of } \\
\text { people }\end{array}$ & Percentage \\
\hline \multirow{3}{*}{ gender } & male & 62 & $56.88 \%$ \\
\hline & female & 47 & $43.12 \%$ \\
\hline & total & 109 & $100 \%$ \\
\hline \multirow{6}{*}{ age } & $18-20$ & 7 & $6.42 \%$ \\
\hline & $21-25$ & 20 & $18.35 \%$ \\
\hline & $26-30$ & 36 & $33.03 \%$ \\
\hline & $31-35$ & 21 & $19.27 \%$ \\
\hline & Above 35 & 25 & $22.93 \%$ \\
\hline & total & 109 & $100 \%$ \\
\hline \multirow[t]{5}{*}{ education } & $\begin{array}{c}\text { Graduated } \\
\text { from high } \\
\text { school }\end{array}$ & 2 & $1.83 \%$ \\
\hline & Bachelor's & 50 & $45.88 \%$ \\
\hline & $\begin{array}{c}\text { Master's and } \\
\text { above }\end{array}$ & 57 & $52.29 \%$ \\
\hline & total & 109 & $100 \%$ \\
\hline & White & 31 & $28.4 \%$ \\
\hline \multirow[t]{6}{*}{ race } & Latino & 39 & $35.8 \%$ \\
\hline & African & 4 & $3.7 \%$ \\
\hline & Native & 0 & 0 \\
\hline & Asian & 19 & $17.4 \%$ \\
\hline & Others & 16 & $14.7 \%$ \\
\hline & total & 109 & $100 \%$ \\
\hline
\end{tabular}

III. THE FINDINGS

A. The Main Variables Descriptive Statistics Analysis

Table III shows the 109 respondents' EIE, EIC, JI, POS score basic descriptive statistics.

TABLE III. EIE, EIC, JI, POS score descriptive statistics

\begin{tabular}{c|c|c|c|c}
\hline $\begin{array}{c}\text { Descriptive } \\
\text { statistics } \\
\text { indicators }\end{array}$ & EIE & EIC & JI & POS \\
\hline Mean & 61.47 & 63.92 & 14.66 & 78.42 \\
Median & 62 & 62 & 15 & 76 \\
Maximum & 81 & 69 & 24 & 104 \\
Minimum & 91 & 86 & 21 & 112 \\
Std. Dev. & 10.39 & 9.80 & 2.70 & 18.02 \\
\hline
\end{tabular}

Table III shows that EIE and EIC median score were both 62 . Based on subsequent analysis, these two median individual ego-identity scores were divided into four types: ego-identity achieved, moratorium, foreclosed, and diffused. These four variables are normally distributed.

\section{B. Correlation Analysis of Individual'S EIE/EIC and JI}

Based on the aforementioned criteria for classification of individual's ego-identity, the 109 respondents were divided into four groups: 23 EI Achieved, 14 EI Moratorium, $34 \mathrm{EI}$ Diffused, and 38 EI Foreclosed.

The correlation coefficient between EIC and JI was 0.010 , which is not significant . In addition, the correlation coefficient between EI Achieved their JI is -0.431 and was significant at the 5\% level.

\section{Regression Analysis of POS and JI}

The regression results are shown in Table 4. As Table 4 shows, the coefficient of the individual's POS was 0.023 and was not significant at the $1 \%$ level of significance. The standardized coefficient of POS was 0.156 and also not significant at the $1 \%$ level.

TABLE IV. Regression analysis of JI $=\alpha+\beta$ POS

\begin{tabular}{|c|c|c|c|c|c|}
\hline Model & \multicolumn{2}{|c|}{$\begin{array}{c}\text { Unstandardized } \\
\text { Coefficients }\end{array}$} & $\begin{array}{c}\text { Standardized } \\
\text { Coefficients }\end{array}$ & & \\
\hline & $\beta$ & $\begin{array}{c}\text { Standar } \\
\text { d error }\end{array}$ & $\beta$ & t-test & significance \\
\hline Intercept & 12.826 & 1.150 & & 11.153 & 0.00 \\
\hline POS & 0.023 & 0.014 & 0.156 & 1.636 & 0.105 \\
\hline
\end{tabular}

D. The Relationship between Different States of EI and JI with POS as a Moderator

Regression (1) above was repeated for each Ego-identity status. The regression analysis shows that, for group EI achieved, when POS increases one Likert rating, JI decreases 0.022 points, however, the results are not statistically significant; For the EI moratorium group, when POS increases one Likert rating, JI improves 0.034 points, the results are not statistically significant; For the EI foreclosed group, when POS increases one Likert rating, JI improves 0.042 points, the results are statistically significant at the $1 \%$ level; Finally, for the EI diffused group, when POS increases one Likert rating, JI improves 0.020 points, the results are not statistically significant.

\section{E. The Impact of Biographical Characteristics on Individual'S EI.}

A single-factor analysis of variance and two independent samples t-test found that gender had significant effects on EI, men had higher EIE and women had higher EIC. Singlefactor analysis of variance and LSD multiple comparison, found that individual's age and education had no significant effects on EI. 


\section{F. The Impact of Biographical Characteristics on Individual'S JI.}

A single-factor analysis of variance and two independent samples t-test found that gender had no significant effect on JI. Single- factor analysis of variance and LSD multiple comparison, found that individual's age and education had no significant effect on JI, but individual's race had significant effect on the degree of JI.

\section{CONCLUSION}

American young adults' EI achieved status negatively correlated with their JI, but not significantly. Individual's POS doesn't show positive effect on their JI. When POS increases, EI Achieved individual's JI does not show significant increment; on the contrary, it decreases but not significant. EI foreclosed individual's JI improves significantly with the increment of POS. Individuals who were in EI diffused or EI moratorium status, their POS both show positive effects on their JI, but not significant. This study also find that gender has significant effect on EI, Men have higher EIE and women have higher EIC. Individual's race has significant effect on their JI. Individual's gender lage does not show significant impact on their JI.Individual's age/education/race dose not show significant affect on their Ego-identity status. Individual's education has significant negative effect on their POS, the higher education they get, the less POS they feel.

\section{DISCUSSION}

To my surprise, this study does not support most of the original hypothesis. American young adults' EI achieved status negatively correlated with their job involvement( not significant); and when their POS was increased, their job involvement even decreased. Individual's perceived organizational support was not positively correlated with their job involvement, it is totally different from the research findings I did in China. But similarly, Individuals who were in EI diffused or EI moratorium status showed improvement in their JI with the increment of POS, but not significant( in China, the correlation is positively significant). The findings is reasonable after careful consideration and reasoning. America is a high individualism country( 91 points for United States and 20 points for China), people prefer prsuing their own life goals, Since American EI achieved people care more about their self-realization, and get more incentive from within, they work in order to meet their career goals and they are more likely to exhibit a high level of job involvement if their organization's values and their own values coincide, and maybe they do their jobs now is only for money to suport their other dreams, so EI achieved people even show negative job involvement. POS does not matter much which is more like a symbol of external excitation. For EI confusion and moratorium individuals, however, if they feel that their organizations support and help them develop their ego-identity, they are stimulated to improve the level of JI, in order to find more self-identification by recognizing the values of work. This finding is consistent with the statement made by Mckelvey and Sekaran (1977).

This study also find that individual's gender has significant effect on EI , men have higher EI Exploration and women have higher EI Commitment; but has no significant effect on the degree of JI. Individual's age and education also have no significant impact on their EI and JI. But individual's education has significantly negative impact on their perceived organizational support, the higher education they have, the less organizational support they perceived. It sounds like a bad news for human resource managers.

\section{POSSIBILITY FOR FURTHER STUDY}

Follow-up research of the influence of demographic variables, EI Status, and the POS influence on JI and how to effectively motivate employees under a cross-cultural environment using United States data to compare Chinese and American individuals under different ethnic and cultural backgrounds would be interesting.

\section{ACKNOWLEDGEMENT}

This research was financially supported by 2013 Social Science Fund of Hubei Provincial Department of Education (1001-06740005).

\section{REFERENCES}

[1] Balistreri B., Busch-Rossnagel, N.A. \& Geisinger,K.F., "Development and preliminary validation of the Ego Identity Process Questionnaire Journal of Adolescence”, vol.18, pp. 179-192, 1995.

[2] Bennion L.D., \&Adams G.R., "A Revision of the extended version of the objective measure of Ego Identity status: An identity instrument for use with late adolescents", Journal of Adolescent Research Summer, vol.2, no.1, pp. 183-197, 1986.

[3] Brown S. P., "A meta-analysis and review of organizational research on job involvement", Psychological Bulletin,vol.120, no.2, pp.235-255, 1996.

[4] Erikson E.H., Identity: Youth and Crisis. New York: Norton, 1968.

[5] Gurin, G., Veroff, J., and Feld, S., Americans view their mental health. New York: Basic Books, 1960.

[6] Kanungo R. N., "Measurement of job and work involvement", Journal of Applied Psychology”, vol.67, no.3, pp.341-349, 1982.

[7] Kanungo R. N., "The concepts of alienation and involvement revisited", Psychological Bulletin, vol.86, pp. 119-38, 1979.

[8] Lodahl T.M., \& Kejner M., "The definition and measurement of job involvement. Journal of Applied Psychological", vol.49, no.1, pp.24-33, 1965.

[9] Lynch P., Eisenberger R., \& Armeli S., "Perceived organizational support: Inferior-versus-superior performance by wary employees", Journal of Applied Psychology, vol.84, pp.467-483, 1999.

[10] McKelvey B., \& Sekaran, U., "Toward a career-based theory of job involvement: A study of scientists and engineers", Administrative Science Quarterly, vol.22, no.2, pp.281-305, 1977.

[11] Rabinowitz S and Hall D.T., "Organization research on job involvement”, Psychological Bulletin, vol.84, pp.265-288, 1997.

[12] Rhoades L., \& Eisenberger R., "Perceived organizational support: A review of the literature", Journal of Applied Psychology, vol.87, no.4, pp. 698-714, 2002. 